\title{
Pengaruh Pupuk Organik Gulma Siam (Chromolaena odorata L.) dan Ampas Bungkil Mimba (Azadiracta indica A.Juss) pada Sifat Kimia Tanah dan Performa Tanaman Padi Hitam
}

\author{
Rizky Fauzi1), Octaviani1), Reynaldi Yunior'1), Vira Kusuma Dewi'2), Santika Sari'3), \\ Sri Hartati2), Dwi Harya Yudistira4), Yongki Umam Sandi1)
}

1) Mahasiswa Program Studi Agroteknologi Pertanian, Fakultas Pertanian UNPAD

2) Departemen Hama Penyakit Tanaman, Fakultas Pertanian, UNPAD

3) Departemen Budidaya Pertanian, Fakultas Pertanian, UNPAD

4) Alumni Program Studi Agroteknologi, Fakultas Pertanian UNPAD

Jl. Raya Bandung Sumedang Km 21 Jatinangor

Korespondensi: vira.kusuma.dewi@unpad.ac.id

\begin{abstract}
A black rice cultivation study was conducted at Kampung Cinenggang, Cileles Villages, Jatinangor. This research analyzed the effect of organic fertilizer such as siam weed compost and neem cake waste to black rice growth and soil chemicals. The experiment was arranged in randomized block design consisted of five treatments and six replications as follow: neem cake waste, siam weed compost, cow manure, urea were used as the $N$ sources by comparing with no application (control). Overall the result of the study showed that there were no significant differences among treatment in plant growth characters such as plant height and SPAD, except control. In tiller number, the effect of neem cake waste and siam weed compost were significant different if compared with other treatments. Furthermore, the effect of neem cake waste gives a positive effects to soil chemicals which in turn enhanced the growth of black rice. it is recommended that organic fertilizers (neem cake waste and siam weed compost) be utilized instead of chemical fertilizer.
\end{abstract}

Keywords: black rice, neem cake waste, organic fertilizer, siam weed compost, plant growth, soil chemicals

\section{PENDAHULUAN}

Padi hitam (Oryza sativa L.) adalah padi lokal yang memiliki karakteristik produksi antosianin dengan intensitas tinggi sehingga warna padi menjadi ungu pekat hingga hitam. Padi hitam di kalangan masyarakat semakin popular dan banyak dikonsumsi (Kristamtini et. al., 2012). Umur padi hitam relatif panjang dan berdaya hasil rendah merupakan faktor pembatas dalam usaha budidayanya sehingga seringkali menurunkan minat petani (Wahdah dan Langai, 2009). Oleh karena itu, upaya dalam mendukung peningkatan produktivitas padi hitam sangat diperlukan dikarenakan padi hitam memiliki peluang yang bagus untuk dibudidayakan dikaitkan dengan manfaatnya bagi kesehatan.

Upaya peningkatan produksi beras seringkali ditekankan pada penggunaan bahan kimia sintetik secara terus menerus sehingga berdampak negatif terhadap lingkungan. Penggunaan bahan kimia yang berlebihan dapat mengakibatkan pencemaran lingkungan, misalnya pencemaran tanah pada lahan pertanian (Adriyani, 2006). Selain itu, kondisi lahan pertanian yang tercemar dapat berakibat pada menurunnya kesuburan tanah dan keanekaragaman hayati sehingga dapat mempengaruhi keseimbangan ekosistem sawah (Lestari, 2009). Oleh karena itu, upaya untuk mendukung pertanian organik semakin ditingkatkan dalam aplikasinya.

Pertanian organik meliputi penggunaan varietas lokal yang relatif masih alami, diikuti dengan pemakaian pupuk organik dan pestisida organik. Adapun pupuk yang digunakan mulai dari pemupukan awal dan lanjutan menggunakan bahan organik (Andoko, 2002). Pupuk organik merupakan 
bahan pembenah tanah yang paling baik dan alami. Pada umumnya pupuk organik mengandung hara makro $\mathrm{N}, \mathrm{P}, \mathrm{K}$ rendah, tetapi mengandung hara mikro dalam jumlah cukup yang sangat diperlukan untuk pertumbuhan tanaman (Sutanto, 2002).

Pemanfaatan bahan organik sebagai pupuk merupakan salah satu upaya dalam mendukung pertanian organik (Kardinan, 2011). Aplikasi bahan organik sebagai pupuk dapat meningkatkan kandungan unsur hara, fisik dan kimia tanah (Widowati, 2009) serta aktivitas organisme tanah (Leszczynska \& Malina, 2011). Adapun beberapa alternatif bahan tanaman yang dapat digunakan sebagai pupuk organik yaitu gulma siam (Choromolaena odonata (L.) R.M.King \& H.Rob.) dan ampas bungkil mimba (Azadirachta indica A.Juss).

Gulma siam adalah sejenis tumbuhan yang hidup liar dilahan kering dan banyak dijumpai pada lahan-lahan terbuka ataupun lahan marjinal. Gulma siam mengandung unsur hara yaitu kandungan karbon, kalsium, magnesium, kalium dan nitrogen yang lebih tinggi bila dibandingkan dengan pupuk kandang sapi (Suntoro dkk., 2001; Suharjo dan Aeny 2011). Lebih lanjut Hakim dan Agustian (2010) melaporkan bahwa pertumbuhan tanaman cabai yang diberi perlakuan pupuk gulma siam dan dikombinasi $50 \%$ dosis pupuk buatan, tidak berbeda nyata dengan tanaman cabai yang diberi 100\% pupuk buatan $\mathrm{N}, \mathrm{P}$, dan $\mathrm{K}$. Hal ini menunjukkan bahwa gulma siam berpotensi digunakan sebagai alternatif pupuk organik.

Potensi bahan organik lainnya adalah ampas bungkil mimba yang memiliki kandungan bahan aktif yaitu azadirachtin, minyak gliserida, polifenol, acetiloksifuranil dekahidrotetrametil acid, ksosiklopentanatofiliran, asetat keton, monoterpen, dan heksahidrosotetrametil (Nurindah dkk., 2012). Menurut Setiawan dan Nandini (2013) ampas bungkil mimba berpotensi sangat baik sebagai bahan pembuatan pupuk dan pemulsaan. Merujuk pada penjelasan di tas, ampas bungkil mimba ini juga masih mengandung bahan aktif pestisida nabati yang bermanfaat mengendalikan organisme pengganggu tumbuhan (OPT) yang berada di dalam tanah, sehingga memiliki dua fungsi ganda yaitu sebagai pupuk organik dan pestisida (Strathie and Zachariades, 2002).

Tujuan penelitian ini adalah mengetahui pengaruh aplikasi pupuk organik gulma siam C. odorata dan ampas bungkil mimba $A$. indica terhadap performa tanaman padi hitam.

\section{BAHAN DAN METODE}

\subsection{Waktu dan Tempat Penelitian}

Penelitian dilaksanakan bulan Mei sampai November 2018 di persawahan Kampung Cinenggang, Desa Cileles, Jatinangor, Kabupaten Sumedang, Jawa Barat dengan ketinggian $\pm 765 \mathrm{~m}$ diatas permukaan laut. Analisis tanah dan pupuk $(\mathrm{C} / \mathrm{N}$ rasio $)$ dilakukan di Balai Penelitian Tanaman Sayuran (Balitsa).

\subsection{Bahan dan Alat}

Bahan yang digunakan dalam percobaan antara lain: benih padi hitam asal Tasikmalaya, aquadest, alkohol 70\%, pupuk NPK Mutiara (16\% N (Nitrogen), 16\% $\mathrm{P}_{2} \mathrm{O}_{5}$ (Phospate), $16 \% \mathrm{~K}_{2} \mathrm{O}$ (Kalium), $0.5 \% \mathrm{MgO}$ (Magnesium), dan 6\% CaO (Kalsium)), Pupuk kotoran sapi (10 ton per ha), pupuk ampas bungkil mimba (10 ton per ha) dan pupuk gulma siam (10 ton per ha)

Alat yang digunakan selama percobaan yaitu : cangkul, caplakan, kertas label, , alat tulis, serta alat laboratorium untuk analisis tanah seperti labu kjeldahl dan peralatan untuk titrasi.

\subsection{Rancangan Percobaan}

Rancangan yang digunakan adalah Rancangan Acak Kelompok (RAK) yang terdiri dari 5 perlakuan jenis pupuk, yang disusun sebagai berikut:

$$
\mathrm{A}=\text { tanpa pupuk }
$$


$\mathrm{B}=$ ampas bungkil mimba (12 kg per plot)

$\mathrm{C}=$ kompos gulma siam $(12 \mathrm{~kg}$ per plot $)$

$\mathrm{D}=$ pupuk kotoran sapi $(12 \mathrm{~kg}$ per plot $)$

$\mathrm{E}=$ pupuk NPK Mutiara (300 g per plot)

Kelima perlakuan di atas diulang sebanyak 6 kali sehingga diperoleh 30 satuan percobaan.

\subsection{Pembuatan Pupuk Organik}

Pembuatan pupuk gulma siam berlangsung selama 4 minggu. Tahap kegiatan yang dilakukan adalah mengumpulkan tumbuhan gulma siam, selanjutnya proses pemilahan dan pencacahan hingga halus agar mudah terdekomposisi dengan cepat. Gulma siam yang telah dicacah kemudian ditambahkan air dan diberikan EM4 sesuai takaran dosis yang diperlukan dan diaduk hingga merata. Setelah itu, gulma siam yang telah tercampur rata dimasukkan ke dalam kotak kayu berukuran 2 × 1 x $1 \mathrm{~m}$.

Selama proses pengomposan, setiap satu minggu sekali diberikan gula pasir dan EM4 secukupnya untuk memberikan nutrisi bagi dekomposer yang digunakan dan dilakukan pembalikan. Apabila bahan organik telah mengalami perubahan warna menjadi hitam dan hancur menjadi remahan maka menandakan bahwa proses pengomposan telah berhasil.

Ampas bungkil mimba diperoleh dari PUSPROMIT HPT, Ampas yang merupakan hasil pengepresan ini dikumpulkan kemudian dikering udarakan. Pengeringan dilakukan untuk menghindari tumbuhnya jamur pada ampas. Setelah kering, ampas bungkil mimba ditimbang sesuai keperluan yang dibutuhkan.

\subsection{Pengolahan lahan, penanaman dan pemeliharaan tanaman}

\section{A. Pengolahan Lahan}

Pada tahap awal pengolahan dilakukan pembajakan tanah sawah dengan tujuan membuat lapisan tanah yang berada di bawah terbalik keatas sehingga aerasi tanah dapat berlangsung dengan baik. Tahap selanjutnya dilakukan pengairan tanah sawah selama seminggu sampai menggenang. Seminggu kemudian dilakukan kembali pengolahan tanah sawah sehingga bongkahan tanah menjadi semakin kecil. Selanjutnya, pada lahan sawah dibuat 30 petakan atau plot dengan ukuran masing-masing petak sebesar $3 \times 4 \mathrm{~m}$. Pada setiap petak perlakuan dibuat saluran inlet-outlet untuk meminimalisasi bercampurnya pengaruh dari pupuk yang digunakan antar petak. Selain itu, setiap petak perlakuan dipisahkan dengan guludan atau bedengan yang luasannya cukup.

\section{B. Persiapan Benih Padi}

Pada tahap awal persemaian, benih diseleksi dengan cara merendamnya menggunakan air yang mengandung garam agar dapat diperoleh benih yang bernas. Selanjutnya, benih yang telah terseleksi, direndam selama kurang lebih 2 x 24 jam dengan air bersih. Tahap berikutnya, benih ditiriskan selama 24 jam dan untuk selanjutnya di semai. Penyemaian benih padi hitam dilakukan pada baki yang berisi media tanam dengan campuran pupuk kandang/bokashi dan tanah bertekstur remah (1:1). Selanjutnya dilakukan penyiraman 2 kali sehari. Pada umur semaian \pm 15 -20 hari, maka tanaman sudah siap pindah tanam.

\section{Penanaman}

Jarak tanam yang digunakan yaitu $30 \times 15$ $\mathrm{cm}$ (Dewi et al., 2017). Penanamn menggunakan sistem tanam tunggal yaitu menanam satu bibit tiap lubang tanam. Bibit yang digunakan ditanam dangkal dengan perakaran horizontal seperti huruf L agar bibit tidak memerlukan energi besar dalam memulai pertumbuhan kembali.

\section{Pemeliharaan tanaman}

Pemeliharaan meliputi pengairan dan penyiangan gulma. Penyiangan gulma 
dilakukan sebanyak 6 kali dimulai pada 1 minggu setelah tanam (MST) dengan rentang penyiangan 7-10 hari. Adapun aplikasi pupuk yang digunakan pada masing masing petak perlakuan diberikan sesuai perhitungan yang ada.

Terkait pengelolaan air, pada saat padi dalam fase vegetatif (belum keluar malai/tempat keluarnya bunga padi) dalam kondisi macak-macak. Setelah padi berumur 25-30 hari maka lahan mulai digenangi hingga setinggi 5-10 cm. Pada saat anakan maksimum berumur 47-55 hari setelah tanam, lahan dalam kondisi kering selama 710 hari. Setelah 7-10 hari dikeringkan, kondisi lahan kembali dibasahi (macak-macak) selama masa pertumbuhan malai, bulir, dan pengisian bulir hingga bernas. Selanjutnya air dikeringkan kembali hingga saatnya panen.

\subsection{Pengamatan Performa Tanaman Padi}

Parameter pengamatan untuk tanaman padi adalah tinggi tanaman, SPAD value, jumlah anakan dan panikel. Jumlah tanaman yang diukur sebanyak 10 tanaman untuk tiap petak perlakuan. Pengamatan dilakukan pada (3 MST, 6 MST, 9 MST, 12 MST, dan 15 MST).

\subsection{Analisis Data}

Data hasil pengamatan diuji dengan uji $\mathrm{F}$ untuk mengetahui adanya perbedaan respons terhadap performa tanaman padi hitam dari setiap perlakuan yang selanjutnya, dilakukan uji stastistika lanjutan dengan menggunakan Uji Tukey pada taraf 5\% menggunakan software open source $\mathrm{R}$.

\section{HASIL DAN PEMBAHASAN}

\subsection{Performa Tanaman Padi}

Berdasarkan hasil pengamatan tinggi tanaman, perlakuan pemupukan berbeda nyata dengan control. Namun, jenis pupuk tidak memberikan pengaruh yang nyata terhadap tinggi tanaman (Tabel 1). Namun terlihat bahwa perlakuan kompos gulma siam cenderung meningkatkan tinggi tanaman padi lebih tinggi daripada perlakuan lainnya. Hal ini berkaitan dengan meningkatnya ketersediaan nitrogen dalam tanah dan serapan nitrogen oleh tanaman padi.

Tabel 1 Pengaruh beberapa perlakuan pupuk terhadap performa tanaman padi hitam

\begin{tabular}{cccc}
\hline \multirow{2}{*}{ Perlakuan } & \multicolumn{3}{c}{ Performa Tanaman Padi } \\
\cline { 2 - 4 } & Tinggi Tanaman $(\mathrm{cm})$ & SPAD Value (Klorofil) & Jumlah Anakan \\
\hline A & $82,89 \mathrm{a}$ & $29,88 \mathrm{a}$ & $12,50 \mathrm{a}$ \\
B & $94,08 \mathrm{~b}$ & $33,97 \mathrm{~b}$ & $18,70 \mathrm{~b}$ \\
C & $95,93 \mathrm{~b}$ & $33,61 \mathrm{~b}$ & $16,73 \mathrm{ab}$ \\
D & $93,59 \mathrm{~b}$ & $33,11 \mathrm{~b}$ & $14,00 \mathrm{a}$ \\
E & $91,61 \mathrm{~b}$ & $31,98 \mathrm{ab}$ & $13,10 \mathrm{a}$
\end{tabular}

Keterangan : Rerata yang diikuti oleh huruf yang sama dalam baris atau kolom menunjukkan tidak berbeda nyata pada $\alpha 5 \%$. $\mathrm{A}=$ kontrol, $\mathrm{B}=$ pupuk ampas bungkil mimba, $\mathrm{C}=$ kompos gulma siam, $\mathrm{D}=$ kompos kotoran hewan, dan $\mathrm{E}=$ pupuk NPK.

Penambahan bahan organik kompos gulma siam dan ampas bungkil mimba dinilai dapat memenuhi kebutuhan untus hara bagi pertumbuhan tanaman padi hitam. Menurut Suntoro, dkk (2001); Dewi dkk., (2018), pupuk organik asal gulma siam dapat dijadikan salah satu alternatif pupuk organik karena mempunyai kandungan $\mathrm{C}, \mathrm{Ca}, \mathrm{Mg}, \mathrm{K}$, dan $\mathrm{N}$ yang lebih tinggi dibandingkan pupuk kandang sapi.

Berdasarkan Tabel 1 nilai SPAD (klorofil) pada semua perlakuan pupuk dan kompos tidak berbeda nyata antar perlakuan kecuali dengan kontrol. Namun secara kuantitatif, nilai SPAD tanaman padi yang diberi perlakuan ampas bungkil mimba cenderung 
lebih tinggi dibandingkan perlakuan yang lain. De Datta (1981) juga menyatakan bahwa fungsi $\mathrm{N}$ bagi tanaman padi adalah dapat meningkatkan proses fotosintesis sehingga secara tidak langsung memiliki nilai klorofil yang tinggi.

Pada Tabel 1 disajikan bahwa jumlah anakan pada perlakuan kompos gulma siam dan ampas bungkil tidak berbeda nyata, namun berbeda nyata dengan control dan pupuk buatan. Walaupun secara kuantitatif terlihat bahwa pupuk ampas bungkil mimba menghasilkan jumlah anakan tanaman padi yang cenderung lebih tinggi daripada perlakuan kompos gulma siam.

Jumlah anakan merupakan hasil atau produk pada fase vegatatif tanaman yang akan menentukan hasil produksi tanaman padi. Menurut Yoshida (1981), peranan nitrogen sangat penting dalam proses pertumbuhan jumlah anakan walaupun secara genetik varietas tanaman menentukan jumlah anakan dan pertumbuhannya.

Menurut Howard et al., (2001) tanaman serealia memerlukan unsur hara $\mathrm{N}$ dan $\mathrm{K}$ yang dapat memacu proses fotosintesis untuk pembentukan anakan. Schmutterer (1990) menyatakan bahwa ampas bungkil mimba sangat berpotensi sebagai bahan organik untuk pertumbuhan tanaman, dikarenakan memiliki 2 peran yaitu sebagai pupuk dan pestisida organik. Ampas bungkil mimba mengandung beberapa komponen aktif pestisida yaitu azadirakhtin, salanin, nimbin, dan meliantriol yang dapat mendukung mekanisme ketahanan tanaman. Selain itu, dilaporkan pula bahwa pada pertanaman lada, ampas bungkil mimba memberikan hasil produksi yang tinggi bila dibandingkan dengan penggunaan pupuk lainnya (info Perkebunan, BBP2TP).

\subsection{Nisbah C/N pada Tanah}

Salah satu unsur hara makro esensial adalah Nitrogen. Hanafiah (2007) menyatakan bahwa peranan utama nitrogen adalah merangsang pertumbuhan khususnya batang, cabang dan daun serta pengaturan fotosintesis dan pemenuhan komponen produksi.

Tabel 2 menyajikan data kadar C-organik dan N-total dalam tanah. Kadar C-organik tertinggi adalah pada ampas bungkil mimba. Nilai C-organik yang tinggi dapat disebabkan oleh aplikasi ampas bungkil mimba dalam keadaan segar. Pupuk ampas bungkil mimba mempunyai kandungan $\mathrm{N}$ yang lebih tinggi dari pupuk kotoran hewan dan kompos gulma siam yaitu sebesar 2,64\%. Tingginya nilai Corganik menyebabkan nilai $\mathrm{C} / \mathrm{N}$ ampas bungkil mimba tertinggi jika disbanding dengan kompos gulma siam. Nilai C/N $10-20$ menunjukkan proses pengomposan yang sudah terjadi dengan baik (Djuarnani dkk., 2009).

Tabel 2 Analisis (C-organik, N, total) dan kondisi awal tanah dan jenis pupuk yang digunakan

\begin{tabular}{lccc}
\hline \multirow{2}{*}{ Keterangan } & \multicolumn{3}{c}{ Analisis Tanah } \\
\cline { 2 - 4 } & $\begin{array}{c}\text { C- } \\
\text { organik } \\
(\%)\end{array}$ & $\begin{array}{c}\text { N total } \\
(\%)\end{array}$ & C/N \\
\hline $\begin{array}{l}\text { Tanah Awal } \\
\begin{array}{l}\text { Pupuk ampas } \\
\text { mimba }\end{array}\end{array}$ & 2,08 & 0,19 & 10,99 \\
$\begin{array}{l}\text { Kompos gulma siam } \\
\text { Kompos kotoran }\end{array}$ & 9,49 & 1,13 & 8,39 \\
hewan & 15,79 & 1,24 & 12,73 \\
\hline
\end{tabular}

Hasil analisis (Tabel 3) kadar C-organik dan $\mathrm{N}$-total tidak berbeda nyata pada pengukuran masa pertanaman dan setelah panen. Namun, nilai $\mathrm{C} / \mathrm{N}$ menunjukan penurunan. Hal ini menunjukkan proses dekomposisi bahan organik oleh mikroorganisme tanah. Dermiyati (1997) menambahkan bahwa bahan organik mampu sebagai energi dan makanan bagi mikroorganisme yang merombak bahan organik menjadi unsur hara seperti N, P dan $\mathrm{K}$. Unsur hara yang dihasilkan dari dekomposisi bahan organik akan menjadi 
unsur hara yang tersedia untuk tanaman. Unsur hara ini menurut Dobermann dan Fairhust (2000) akan digunakan untuk pertumbuhan tanaman seperti menambah tinggi tanaman, jumlah anakan, serta memperbaiki kualitas tanaman.

Tabel 3 Analisis tanah pada masa pertanaman dan setelah panen pada persawahan padi hitam.

\begin{tabular}{ccccccc}
\hline Perlakuan & \multicolumn{2}{c}{ C-organik (\%) } & \multicolumn{2}{c}{ N-total(\%) } & \multicolumn{2}{c}{ C/N ratio } \\
\cline { 2 - 7 } & $\begin{array}{c}\text { masa } \\
\text { pertanaman }\end{array}$ & $\begin{array}{c}\text { setelah } \\
\text { panen }\end{array}$ & $\begin{array}{c}\text { masa } \\
\text { pertanaman }\end{array}$ & $\begin{array}{c}\text { setelah } \\
\text { panen }\end{array}$ & $\begin{array}{c}\text { masa } \\
\text { pertanaman }\end{array}$ & $\begin{array}{c}\text { setelah } \\
\text { panen }\end{array}$ \\
\hline A & 2,22 & 1,92 & 0,20 & 0,22 & 11,10 & 8,93 \\
B & 2,65 & 2,32 & 0,22 & 0,20 & 12,02 & 11,60 \\
C & 2,57 & 2,19 & 0,24 & 0,24 & 10,69 & 9,10 \\
D & 2,44 & 2,19 & 0,22 & 0,21 & 11,09 & 10,66 \\
E & 2,31 & 2,06 & 0,21 & 0,20 & 11,24 & 10,28
\end{tabular}

Keterangan: $\quad \mathrm{A}=$ kontrol, $\mathrm{B}=$ pupuk ampas bungkil mimba, $\mathrm{C}=$ kompos gulma siam, $\mathrm{D}=$ perlakuan kompos kotoran hewan, dan E = pupuk NPK

\section{KESIMPULAN}

Penggunaan pupuk ampas bungkil mimba dan kompos gulma siam mampu meningkatkan tinggi tanaman, nilai SPAD (klorofil) dan jumlah anakan pada tanaman padi. Sedangkan terkait sifat kimia tanah, penggunaan pupuk ampas mimba cenderung lebih tinggi mempengaruhi ketersediaan $\mathrm{N}$ ditanah sehingga mudah terserap oleh tanaman.

\section{DAFTAR PUSTAKA}

Adriyani, R. 2006. Usaha Pengendalian Pencemaran Lingkungan Akibat Penggunaan Pestisida Pertanian. Jurnal Kesehatan Lingkungan 3 (1): 95-106.

Andoko, A. 2002. Budidaya Padi secara Organik. Jakarta : Penebar Swadaya.

De Datta, S.K. 1981. Principles and Practices of Rice Production. A Wiley-Interscience Publication. New York: John Wiley \& Sons.

Dermiyati, 1997. Pengaruh mulsa terhadap aktivitas microorganisme tanah dan produksi jagung hibrida C1. Jurnal Tanah Tropika, 5: 63-68.

Dewi, V. K Sato, S and Yasuda, H. 2017. Effects of a mud snail Cipangopaludina chinensis laeta (Architaenioglossa: Viviparidae) on the abundance of terrestrial arthropods through rice plant development in a paddy field. J. Applied Entomology and Zoology. 52(1):97-106.

Dewi, V.K., Putra, N.S., Purwanto, B., S, Hartati., S, Sari. 2018. Aplikasi Kompos Gulma Siam Chromolaena odorata terhadap Sifat Kimia Tanah dan Performa Tanaman Cabai. Soilrens Jurnal, 16 (1): $65-72$.

Djuarnani, N., Kristian, dan S.S. Setiawan. 2009. Cara Cepat Membuat Kompos. Jakarta: Agromedia Pustaka.

Dobermann, A. and T. Fairhust. 2000. Rice : Nutrient Disorders and Nutrient Management. Makati : Potash and Phosphate Institute (PPI) and Internasional Rice Research Institude (IRRI). 
Hakim, N dan Agustian. 2010. Pemanfaatan Gulma Kirinyuh sebagai Sumber Bahan Organik untuk Tanaman Sawo pada Lahan Reritis Dikecamatan Rambatan Kabupaten Tanah Datar. Laporan Penelitian.

Hanafiah, K.A. 2007. Dasar-dasar Ilmu Tanah. Jakarta : Raja Grafindo Persada.

Howard D.D., C.O. Gwathmey, M.E. Essington, R.K. Roberts and M.D. Mullen. 2001. Nitrogen fertilization of no-till cotton on loess-derived soils. Agron. J., 93: 157-163.

Kardinan, A. 2011. Penggunaan pestisida nabati sebagai kearifan lokal dalam pengendalian hama tanaman menuju sistem pertanian organik. Pengembangan Inovasi Pertanian 4 (4): $262-278$

Kristamtini, Taryono, P. Basunanda, R.H. Murti, Supriyanta, S. Widyayanti, Sutarno. 2012. Morphological of genetic relationships among black rice landraces from Yogyakarta and surrounding areas. ARPN J. Agric. Biol. Sci. 7:982-989.

Leszczyńska D., K. Malina. 2011. Effect of organic matter from various sources on yield and quality of plant on soils contaminated with heavy metals. Ecological Chemistry and Engineering S. 18 (4): 501-507.

Lestari, A. P. 2009. Pengembangan pertanian berkelanjutan melalui substitusi pupuk anorganik dengan pupuk organik. Jurnal Agronomi 13 (1): 3844.

Nurindah, D.A Sunarto dan Sujak. 2012. Efektivitas dan kompatibilitas ekstrak biji mimba untuk mengendalikan kompleks penggerek buah kapas. Bulletin Littro 23 (1): 48-60.
Schmutterer, H. 1990. Properties and potential of natural pesticides from the neem tree, Azadirachta indica. Annual Review Entomology, 35: 271297.

Setiawan, O dan Nandini, R. 2013. Pemanfaatan Hidrogel dan Pupuk Organik sebagai Pembenah Tanah dalam Rehabilitasi lahan Kritis Berbasis Mimba (Azadirachta indica A.Juss). Lombok : Balai Penelitian Teknologi Hasil Hutan Bukan Kayu (BPTHHB).

Suharjo, R dan Aeny, T.R. 2011. Eksplorasi Potensi gulma siam (Chromolaena odorata) sebagai biofungisida pengendali Phytophthora palmivora yang diisolasi dari buah kakao. J. Hpt Tropika. 11 (2): 201 - 209.

Suntoro, S., E. Handayanto, dan Soemarno. 2001. Penggunaan bahan pangkasan kirinyuh (Chromolaena odorata) untuk meningkatkan ketersediaan $\mathrm{P}$, $\mathrm{K}$, Ca, dan Mg pada Oxic Dystrudepth di Jumapalo, Karanganyar, Jawa Tengah. Agritivia, 23(1): $20-26$.

Sutanto, R. 2002. Pertanian Organik. Kanisius, Yogyakarta.

Strathie, L. W. and Zachariades, C. 2002. Biological control of chromolaena orodata in South Africa: developments in reseach and implementation. In Zachariades, C, R. Muniarappan, and L.W. Strathie (Eds). Proceedings The Fifth International Workshop on Biological Control and Management of Chromolaena odorata. Durban, 23 25 October 2000. P 74 - 79.

Wahdah, R. dan B.F. Langai, 2009. Observasi varietas padi lokal di lahan pasang surut Kalimantan Selatan. Agroscientiae 16(3):177184. 
Widowati, L.R. 2009. Peranan pupuk organik terhadap efisiensi pemupukan dan tingkat kebutuhannya untuk tanaman sayuran pada tanah Inseptisols Ciherang. Jurnal Tanah Tropika. 14:221-228.

Yoshida, S. 1981. Fundamental of Rice Crop Science. Los Banos : The International Rice Research Institute. 